BLS 35, No 1 2009. DOI: http://dx.doi.org/10.3765/bls.v35i1.3619

(published by the Berkeley Linguistics Society and the Linguistic Society of America)

\title{
Arab American Ethnicity and the Northern Cities Shift ${ }^{*}$
}

\author{
SAI SAMANT \\ University of Michigan
}

\section{Introduction}

Sociolinguists have a tradition of studying the social patterning of phonetic variation to understand how sound changes spread through different kinds of speakers and communities. While the bulk of these studies has been on language use and variation among speakers of white ethnicity, a significant amount of work has also focused on minority speakers (particularly African Americans), and sociolinguists continue to expand the breadth of their research on the linguistic practices of ethnic minorities in the United States. Yet, large gaps in the study of widespread, regional linguistic phenomena remain; we still know little about how and to what extent ethnic minorities use linguistic variables of regional sound changes that are often (implicitly and explicitly) associated with white speakers (Fought 2002:457). Labov's (1994:508) assertion that ethnic minority speakers do not participate in mainstream sound changes has also shaped research in this area to some extent. Though early studies of ethnic minority speakers gave evidence that they were not using the variables of mainstream sound changes, Fought (2002:457) observes that these early findings have been over-generalized and have at times led to an assumption that no ethnic minorities use variables of mainstream sound changes. Several studies, however, show complex relationships between the ethnic identity of speakers' language variation (e.g. Fought 1999, Mendoza-Denton 1997), suggesting that the intersection of regional sound change and ethnicity is in fact a fruitful site of research.

This paper presents findings from a study of Arab American high school students in Southeastern Michigan. I examine their use of two vocalic variables associated with the Northern Cities Shift, a widespread, regional set of vowel changes. My findings show that the variation of these two variables is linked to local distinctions within the ethnic category of Arab American.

\footnotetext{
* Thank you to Lauren Squires and Taylor Rielly for valuable comments and suggestions.
} 


\section{Sai Samant}

\section{Background}

Research for this study took place during the 2006-2007 school year at Mercer High School in Dearborn, MI, a suburb of Detroit. ${ }^{1}$ Dearborn, where Arab Americans make up about $30 \%$ of the city's 130,000 residents (U.S. Census Bureau 2003), serves as a social, political, and cultural hub for the large and diverse Arab American community in Southeastern Michigan. Mercer High School's school district does not keep official demographic records of the Arab American population, as Arab American students are classified racially as white. But administrators, teachers, and students all suggest that at least $85-90 \%$ of Mercer's 2,400 students are Arab American (less than 2\% of students are African American; the rest are white/European American).

There are many signs of Arab (and Muslim) culture at Mercer, which are closely intermingled with the day-to-day practices of any typical American high school. Girls in headscarves (about half the female students) wear Detroit Pistons basketball jerseys and letterman's jackets. During Ramadan, the month of fasting in Islam, classrooms are made available for fasting students who do not want to go the cafeteria; yet, fasting football players still show up to team practice and to games. Chicken shawarma is served alongside pizza in the cafeteria.

In addition to these non-linguistic signs, Arabic language is also used regularly. Signage at the school (e.g. for visitor parking) is often in both English and Arabic. Many teachers, administrators, and students all regularly use Arabic, and several Arabic words have entered into the vocabulary of all students (e.g. wallah 'I swear'), not just those who speak Arabic fluently. Noor, a 17-year-old Iraqi senior, explains that someone who is "such an Arab" would "probably say...'wallah' or 'bro' or 'cuz' after every word", suggesting that the stereotype of an Arab at Mercer uses both Arabic and English slang. ${ }^{2}$ The word cuz also highlights a running joke that all Arabs at Mercer and in Dearborn are related. As Reem, a Lebanese student, says about Dearborn:

You can walk into a place and know people. You feel like everybody is your family. (.)

Most of the time everybody in Dearborn is your family but otherwise (.5) because a lot of us Lebanese people have a lot of cousins.

Reem's quote also equates "everybody in Dearborn" with "Lebanese people". This temporary erasure of non-Lebanese Arabs (and non-Arabs) in Dearborn is not uncommon among Lebanese students. The demographics of the Arab American students at Mercer reflect those of the city. Most of Dearborn's Arab American population is an established, economically successful Lebanese Muslim

\footnotetext{
${ }^{1}$ Mercer High School and all participant names are pseudonyms.

${ }^{2}$ Students, whether born in the U.S. or abroad, regularly used Arab and Arabic to refer to their ethnicity. I use Arab American in part to follow other labels for ethnic minorities (e.g. African American, Asian American), but this does not align with local labels used by students. Future work will further address this issue.
} 


\section{Arab American Ethnicity and the NCS}

community, but recent waves of migration from the Middle East have brought Iraqi refugees of the two Gulf Wars and families from Yemen, Palestine, Jordan, and Syria. Alex, a U.S.-born Syrian student, observed:

\footnotetext{
Most of the school, their nationality is Lebanese. So they place theirself as higher class than like Iraqis and Yemenis... They think they're like the cool ones. Cause it's like the most populated here. You don't see much attraction. The Iraqis and the Yemenis they're always looked down on. Who are you? You're garbage.
}

Alex's description highlights divisions between the Lebanese students and the Iraqi and Yemeni students, and suggests a hierarchy in which Lebanese students are in a dominant position within the school. Alex's observations are similar to those of other students and to my own observations during my visits to the school. On more than one occasion I saw Lebanese students vehemently object to being categorized as anything other than Lebanese. These hierarchical divisions based on local, within-ethnic category distinctions may play an important role in the social landscape of the school and thus the social variation of linguistic variables.

\section{The Linguistic Variables}

I examine two vocalic variables: the raising of /æ/ and the backing of $/ \varepsilon /$. Both of these variables are part of the set of sound changes known as the Northern Cities Shift (NCS). The NCS, shown in figure (1), is associated with speakers in urban and suburban areas stretching from the Mississippi River to New England (Labov 1994). The shift is well-studied, particularly among white speakers, in the urban centers of Detroit, Buffalo, and Chicago (e.g. Labov, Yaeger, and Steiner 1972, Gordon 2001).

$$
\text { Diagram of the Northern Cities Shift vowel shifts (Labov 1994:191) }
$$

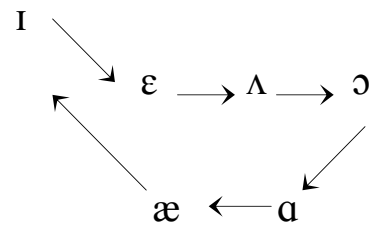

Studies of the NCS have linked it to a variety of social dimensions, including community size and location, social class, gender, and ethnicity. Here, I focus on findings related to gender and ethnicity, though it is important to note that these findings often intersect with other social factors (and with each other).

Research in sociolinguistics suggest that women tend to lead men in the use of new or innovative variants of sound change variables (Labov 2001), and studies on the NCS variables among white speakers tend to confirm this finding. Gordon's (2000) study of the NCS in two small towns in Michigan finds that women lead men in four out of six NCS variables (/I, æ, a, and $\mathrm{s} /$ ). Herndobler's 
Sai Samant

(1993) study of working-class speakers in Chicago shows that women lead men in /æ/-raising, which she argues is linked to the community's working-class norms and expectations, women's jobs in nearby more affluent towns, and genderdifferentiated interests in preserving cultural norms. Eckert's (2000) study of high school students in suburban Detroit shows that use of NCS variables is linked to both gender and a local identity distinction between Jocks and Burnouts, where Burnout girls use the most extreme NCS variants to index an urban and workingclass identity, but Jock girls lead in use of variables associated with the suburban and institutional identities supported by the school.

Other studies have examined speakers' ethnic identity in relation to the NCS variables. Knack (1991) investigates /o/-backing among Jewish and non-Jewish speakers in Grand Rapids, MI, and finds a strong correlation between the Jewish participants' network ties to a geographically-distant and ethnically-like community in New York City and their use of backed (non-NCS) variants of $/ 0 /$. NonJewish participants, who don't have ties to New York City, have overall more / / $/$ fronting, characteristic of the NCS. In Gordon's (2000) study of three NCS variables (/æa, a, and $\varepsilon /$ ) in white, Mexican American, African American, and mixed-ethnicity speakers in Indiana, he finds that the NCS is not very wellestablished in this region, and that, to the extent the NCS is present, it is still generally restricted to the white speakers in his study. Fought (2006:145-146), however, argues that Gordon's generalization about the speakers obscures variation among individual speakers. She notes that several of the mixed-ethnicity speakers and one of the Mexican American speakers use NCS variants at rates comparable to the white speakers. Roeder's (2006) study of Mexican Americans in Lansing, MI, show age and gender differentiation within the community. She finds that younger women produce more fronted variants of /æ/ than other participants in the study, while patterns for three other NCS vowels $(/ \varepsilon, \curvearrowright$, and $a /)$ do not show significant use of NCS variants.

These studies suggest that both gender and ethnicity are likely to be relevant to understanding the social variation of NCS variables. Based on past findings, we might expect the female students to lead male students in use of the NCS variants, and we might also expect an overall picture of Arab American students to show little use of NCS variables. I consider the effects of gender on the variation of two linguistic variables, which I discuss below. I also examine briefly the effects of Arab American ethnicity, but my analysis focuses on intra-ethnic distinctions between Lebanese and non-Lebanese students, based on the findings from interviews and ethnographic observations that this distinction is socially salient for students.

\section{Data and Methods}

The data for this study come from sociolinguistic interviews of 15 students at Mercer High. Interviews took place in a small carpeted room at the high school and were recorded on a steady-state digital recorder. A baseline speaker, a native of a nearby Detroit suburb whose data also come from a sociolinguistic interview, 
is included to provide a reference point for the NCS. The table in (2) provides basic demographic information about the 16 speakers.

Information about speakers
\begin{tabular}{|l|l|l|l|}
\hline Speaker & Gender & Nationality & Age at time of Immigration \\
\hline Aisha & F & Jordan & 1 \\
\hline Alex & M & Syria & US-born \\
\hline Asad & M & Lebanon & US-born \\
\hline Bilal & M & Lebanon & US-born \\
\hline Dee & F & Ira & 2 \\
\hline Hamze & M & Lebanon & US-born \\
\hline Jamil & M & Lebanon & US-born \\
\hline Lina & F & Sierra Leone & 6 months \\
\hline Noor & F & Iraq & 1 \\
\hline Rasim & M & Lebanon & US-born \\
\hline Reem & F & Lebanon & US-born \\
\hline Shadya & F & Lebanon & US-born \\
\hline Zahrah & F & Lebanon & US-born \\
\hline Zeinab & F & Lebanon & US-born \\
\hline Baseline & F & n/a & US-born \\
\hline
\end{tabular}

As close to 30 tokens as possible of each vowel were extracted using the Praat acoustic analysis application (http://www.fon.hum.uva.nl/praat/). Measurements of the first and second formants were taken at the midpoint of each token's vowel nucleus, and these measures were normalized using Lobanov's formula, which minimizes differences between speakers due to vocal tract size while preserving differences based on social factors (see Adank, Smits, and van Hout (2004) for further discussion). ${ }^{3}$ All statistical tests are performed on normalized data. For /æ/-raising, I look at measures of F1, the acoustic correlate of vowel height; for / $\varepsilon$ /-backing, I look at F2 measures, the acoustic measure which corresponds to the front-back vowel dimension.

\section{Results}

\subsection{Overview}

An initial comparison between the students at Mercer and the baseline speaker provides information about the presence of the NCS in the Mercer students' data. Figure (3) provides an overview of part of the vowel space (including four other vowels to provide context and relative positioning). As the figure shows, the overall pattern for the average Mercer speaker is quite similar to the baseline

\footnotetext{
${ }^{3}$ Lobanov's formula: normalized $\mathrm{F}_{\mathrm{n}}=\left(\mathrm{F}_{\mathrm{ni}}-\mu_{\mathrm{i}}\right) / \delta$, where $n$ is the formant number (F1 or F2), $\mu$ is the mean value of the relevant formant frequency for all vowels in speaker $i$ 's vowel system, and $\delta$ is the standard deviation of that same mean formant $\left(\mu_{i}\right)$. Normalization included measures from up to 30 tokens of $/ \mathrm{i}$, e, $æ, \varepsilon, \mathrm{u}, \mathrm{o}, \Lambda, \mathrm{a} /$ to balance out the vowel space.
} 


\section{Sai Samant}

speaker; /æ/ is raised (relative to $/ \varepsilon /$ and to $/ \mathrm{a} /$ ) and $/ \varepsilon /$ is backed (relative to /e/ and to $/ \mathfrak{a} /$ ).

Differences emerge, however, when Lebanese and non-Lebanese speakers are separated, as shown in Figure (4). While the Lebanese speakers'/æ/-raising and $/ \varepsilon /$-backing still look quite similar to the baseline speaker, the non-Lebanese speakers' $/ æ /$ and $/ \varepsilon /$ averages pattern quite differently. For the non-Lebanese speakers, their average /æ/ does not appear to be nearly as raised as either the Lebanese speakers' average or the baseline speaker's average, and $/ \varepsilon /$ is not as far back as either the Lebanese speakers' average or the baseline speaker's average. Results of statistical tests on these differences are discussed below.

(3) Average formant values for all speakers and baseline speaker

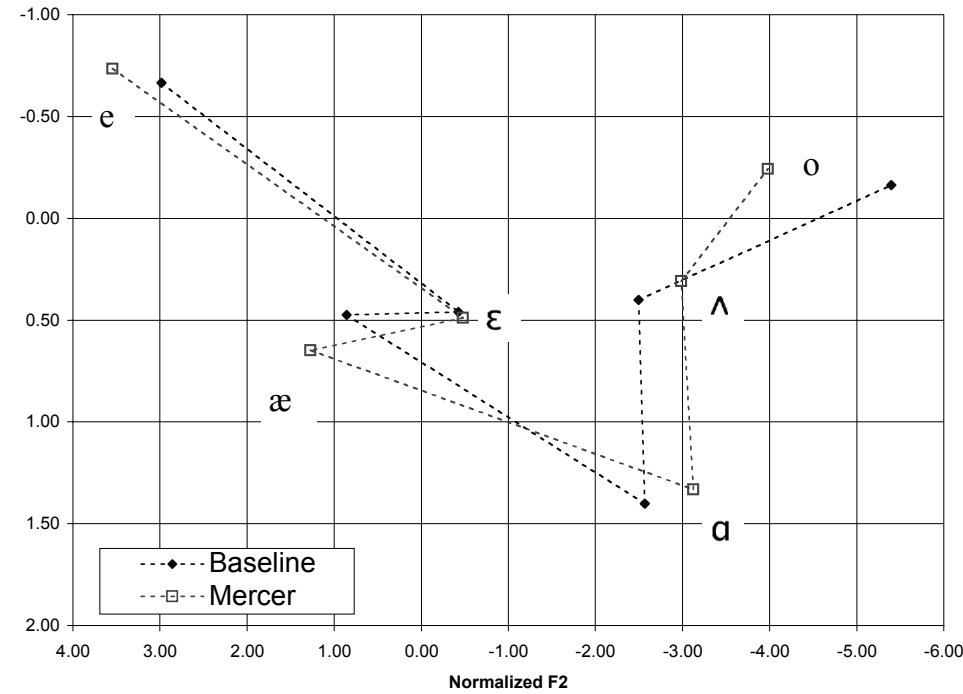

(4) Average formant values for Lebanese and non-Lebanese speakers

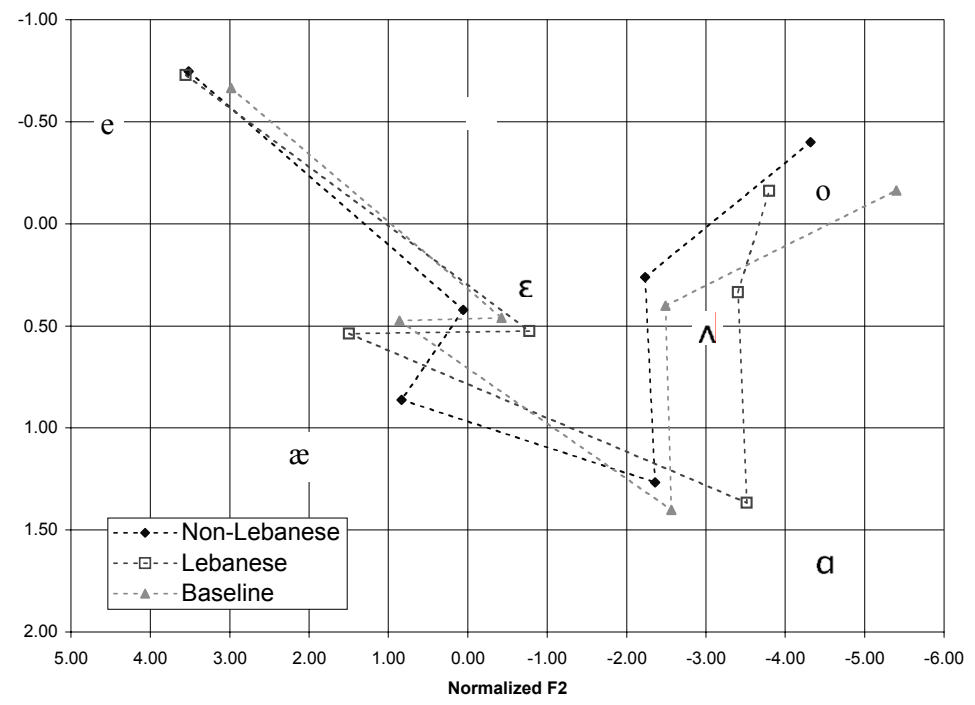




\section{Arab American Ethnicity and the NCS}

\section{2. / / $/$-backing}

Two measures are used to assess the backing of $/ \varepsilon /$ : the F2 of $/ \varepsilon /$ and the difference measure between the F2 of / $/$ / and the F2 of /e/, since /e/ is relatively stable within the vowel systems of speakers in the NCS region.

Figure (5) shows the two measures (F2 and F2-difference) for males and females. U-test results (see figure (6) for details) showed significant differences between males females for both the F2 of $/ \varepsilon /(p=.001)$ and the F2-difference measure $(\mathrm{p}=.000)$. As figure (5) indicates, males had a greater F2-difference and smaller F2 values, both of which suggest that the males in this study have an $/ \varepsilon /$ that is, on average, farther back than that of the females.

Results of a u-test (see Figure (8) for details) comparing Lebanese and nonLebanese students were significant for both the F2 $(\mathrm{p}=.000)$ and the F2-difference measure $(p=.000)$. Lebanese speakers, as shown in Figure $(7)$, have an overall smaller F2 and a greater F2 difference, both suggesting that their / $\varepsilon /$ variants are on average farther back than the non-Lebanese students.

(5) F2 and F2-difference measures for / $\varepsilon$ /-backing by speaker gender

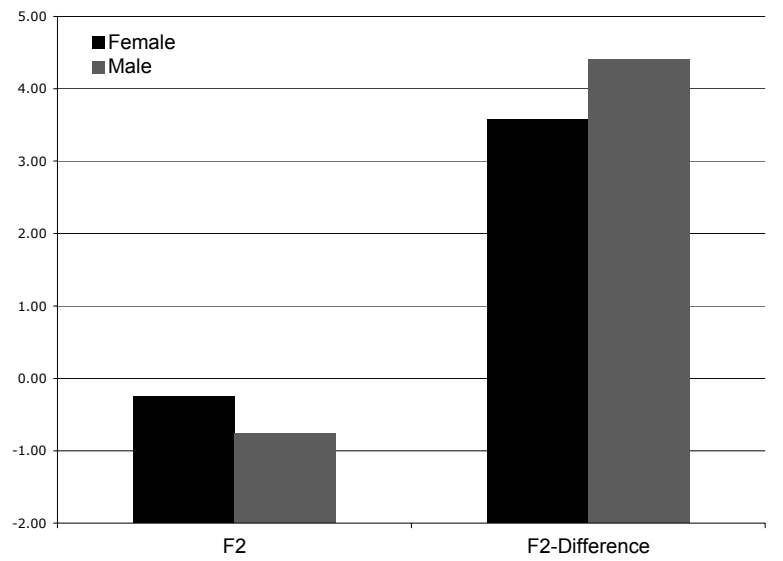

(6) U-test results for $/ \varepsilon /$-backing in male and female speakers

\begin{tabular}{|ll|r|r|r|}
\hline & Gender & N & Mean Rank & \multicolumn{1}{c|}{ Sum of Ranks } \\
\hline F2 & Female & 261 & 256.48 & 66941.00 \\
& Male & 214 & 215.46 & 46109.00 \\
& Total & 475 & & \\
\hline F2-Difference & Female & 261 & 206.11 & 53796.00 \\
& Male & 214 & 276.89 & 59254.00 \\
& Total & 475 & & \\
\hline
\end{tabular}

\begin{tabular}{|l|r|r|}
\hline & \multicolumn{1}{|c|}{ F2 } & F2-Difference \\
\hline Mann-Whitney U & 23104.000 & 19605.000 \\
Significance (2-tailed) & .001 & .000 \\
\hline
\end{tabular}




\section{Sai Samant}

(7) F2 and F2-difference measures for / $/ \varepsilon /$-backing for Lebanese and nonLebanese speakers.

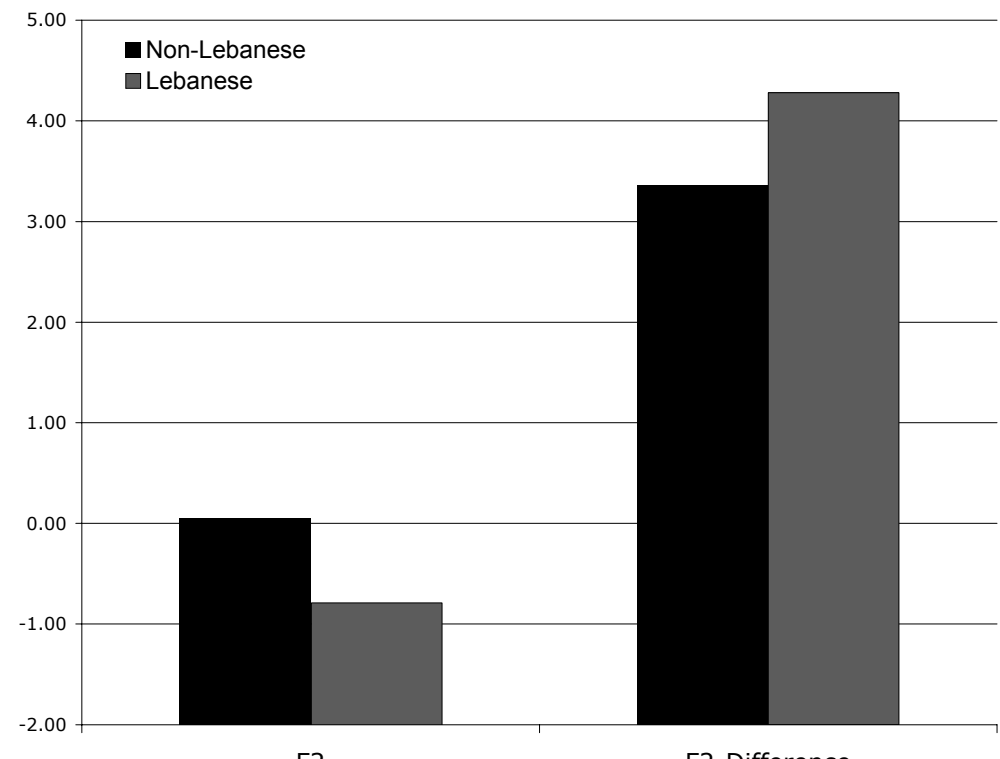

F2

F2-Difference

(8) U-test results for $/ \varepsilon /$-backing in Lebanese and non-Lebanese speakers

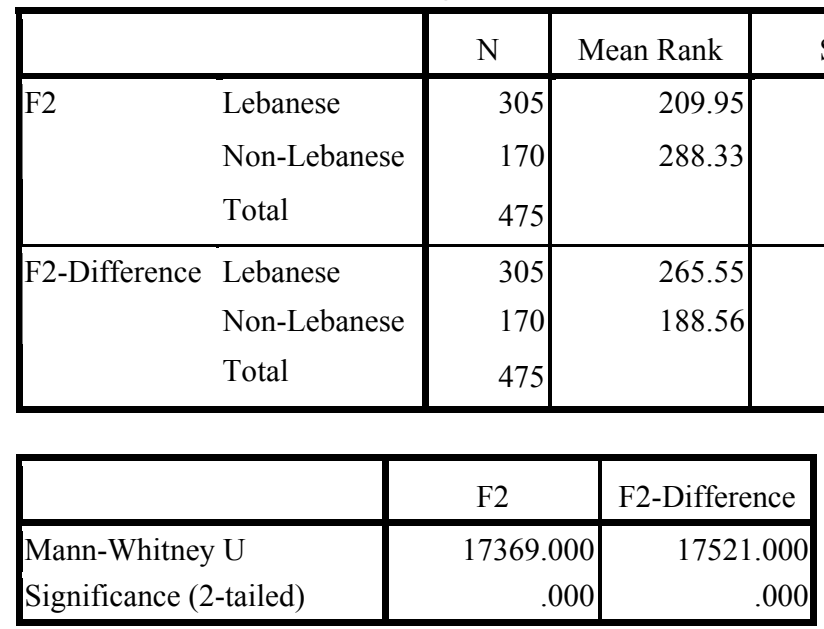

Figure (9) gives the average F2 of $/ \varepsilon /$, arranged from the speaker with least backed $/ \varepsilon /$ to the most backed speaker. The non-Lebanese speakers tend to be at the left, or least backed, end of the graph, while the speakers at the right, or most backed, end of the graph are Lebanese. The baseline speaker is roughly in the middle of the speakers, suggesting that some of the Lebanese speakers have $/ \varepsilon /$ variants that are more backed than even the baseline speaker. Though the gender differences are statistically significant, a similar kind of clustering is not apparent (e.g., the female students are not clustered at the left end of the graph). 
(9) Average F2 of / $\varepsilon$ / by speaker, including baseline speaker.

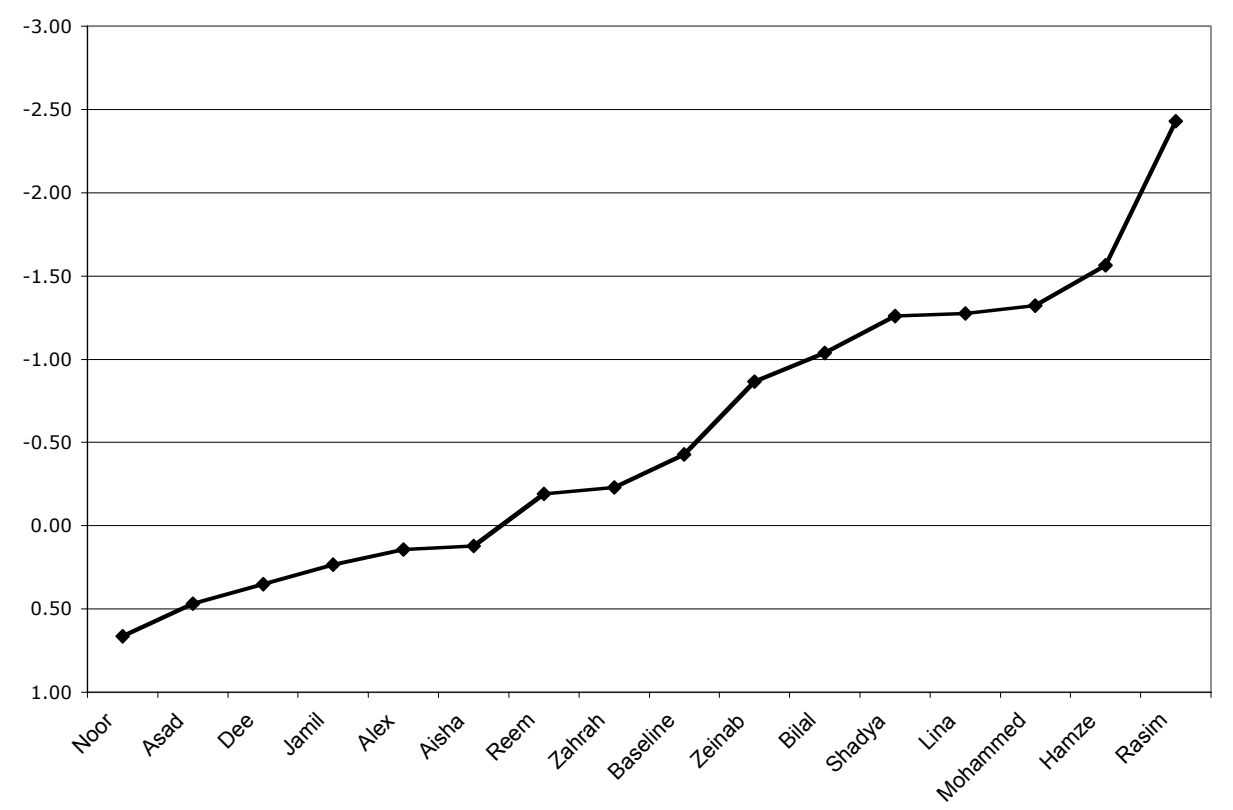

\section{3. /ar/-raising}

To investigate /æ/-raising, I also used two measures: the Fl of /æ/ and an F1difference measure (between the F1 of /e/ and of /æa/), to again get a measure of relative raising. U-tests (see figure (10) for details) on the two /æ/ measures between female and male students showed no significant differences (for F1, $\mathrm{p}=$ .533; for F1-difference, $\mathrm{p}=.456$ ) between the two groups (to save space, figures of these non-significant differences are not included). Between Lebanese and nonLebanese students, a u-test showed significant differences between the two groups for both the $\mathrm{F} 1$ of $/ \mathfrak{x} /(\mathrm{p}=.000)$ and the F1-difference $(\mathrm{p}=.000)$. Lebanese students'

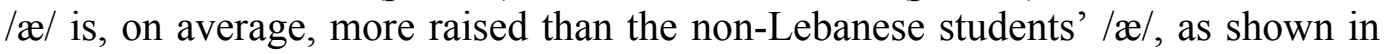
Figure (11).

(10) U-test results for $/ æ /$-raising in Lebanese and non-Lebanese speakers.

\begin{tabular}{|ll|r|r|r|}
\hline & N & Mean Rank & \multicolumn{1}{c|}{ Sum of Ranks } \\
\hline F2 & Lebanese & 366 & 305.08 & 111660.00 \\
& Non-Lebanese & 188 & 223.80 & 42075.00 \\
& Total & 554 & & \\
F2-Difference & Lebanese & 366 & 252.99 & 92593.00 \\
& Non-Lebanese & 188 & 325.22 & 61142.00 \\
& Total & 554 & & \\
\hline
\end{tabular}

\begin{tabular}{|l|r|r|}
\hline & F2 & F2-Difference \\
\hline Mann-Whitney U & 24309.000 & 25432.000 \\
Significance (2-tailed) & .000 & .000 \\
\hline
\end{tabular}




\section{Sai Samant}

(11) F1 and F1-difference of /æ/ for Lebanese and non-Lebanese students.

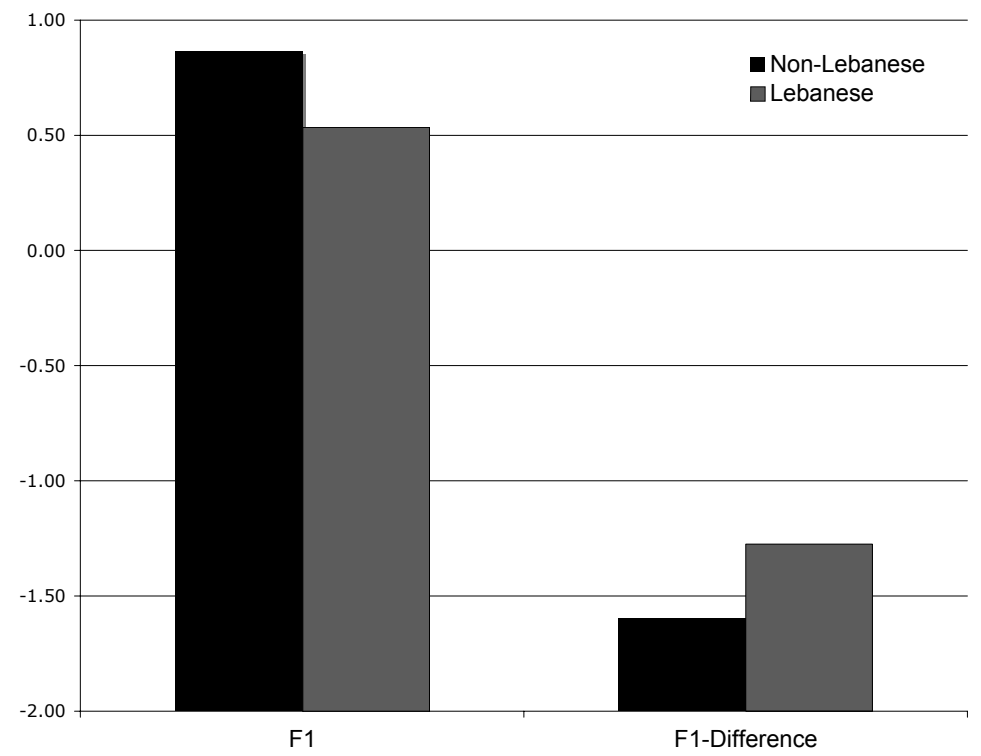

Figure (12) shows the F1 of /æ/ from most raised (the lowest F1) speaker to least raised (the highest F1). Non-Lebanese speakers are clustered at the right end (least raised) end of the graph, as they were with $/ \varepsilon /$-backing.

(12) Average F1 of /æ/ by speaker, inlcuding baseline speaker.

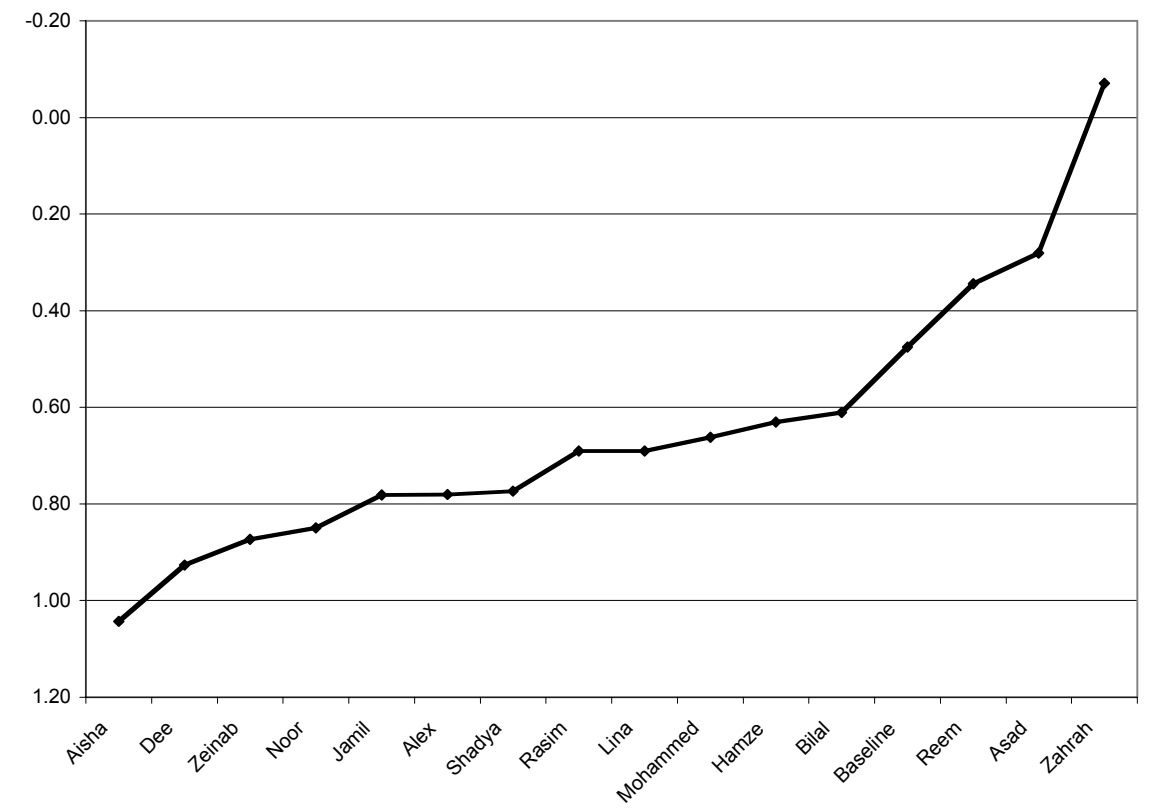




\section{Arab American Ethnicity and the NCS}

\section{Discussion and Conclusion}

The results of this study show significant differences between men and women for $/ \varepsilon /$-backing, in which men appear to be leading women in $/ \varepsilon /$-backing. There are no significant differences between men and women in /æ/-raising. Average F2 values of $/ \varepsilon /$ for individual speakers do not indicate a clear division between men and women. I plan to further investigate these differences by considering the effects of individual speakers on the overall variation, and the interaction of gender with other social factors such as use of Arabic, religious practice, and community orientation.

The results also show that a local distinction within Arab ethnicity, between Lebanese and non-Lebanese students, is related to differences in both /æ/-raising and / $\varepsilon$ /-backing. Minority speakers' use of NCS-variants is often framed as "participation" in or accommodation to mainstream (or white) linguistic patterns (Labov 2001, Gordon 2000, Roeder 2006), which implies that these variants are somehow inherently or essentially linked to white speakers. But, as Fought (2006:149) argues, based on her research on Southern California Latino speakers' use of features associated with California vowel shifts, ethnic minorities can and do use these so-called mainstream features to convey social meaning that is locally understood, and which, crucially, is not tied to affiliation with white ethnicity.

This study demonstrates the importance of accounting for intra-ethnic distinctions that do not usually get addressed in studies on language and ethnicity (Fought 2006: 148). A study that simply compares Arab American speakers to white speakers would not reveal variation tied to intra-ethnic distinctions. The findings of this study suggest that Arab American speakers use linguistic resources of the NCS to index differences among themselves. This use by Arab American speakers of NCS variables to mark an intra-ethnic distinction, supported by testimony about these distinctions by speakers themselves, challenges the prevalent view of the NCS as a mainstream sound change associated with white norms and practices. I do not suggest that Arab Americans are "participating" in the norms of the white mainstream. The students at Mercer High School see their world as primarily Arab, referring to their school as "all Arab", or referring to Dearborn as "Arabtown". In this context, an analysis that takes for granted the presence of a dominant white culture that minority speakers can "accommodate" to is misguided. Rather, the symbolic resources of NCS variation are available to all speakers in the NCS region, not just white speakers, and as such, can be used to index a variety of social dimensions.

The findings of this study are the first step in my analysis and future analysis will take into account linguistic factors (e.g. vowel duration and following phonological context) known to have an effect on vocalic variation. I will also consider additional social dimensions (e.g. age at time of immigration, level of religious practice, Arabic language use) and the interaction between them. 
Sai Samant

\section{References}

Adank, Patti, Roel Smits, and Roeland van Hout. 2004. A comparison of vowel normalization procedures for language variation research. Journal of the Acoustical Society of America 116:3099-3107.

Eckert, Penelope. 2000. Language variation as social practice. Oxford: Blackwell.

Fought, Carmen. 1999. A majority sound change in a minority community: /u/fronting in Chicano English. Journal of Sociolinguistics 3(1):5-23.

Fought, Carmen. 2002. Ethnicity. In J.K. Chambers, P. Trudgill, and N. SchillingEstes, eds., The handbook of language variation and change 444-472. Malden, MA: Blackwell.

Fought, Carmen. 2006. Language and ethnicity. Cambridge: Cambridge UP.

Gordon, Matthew. 2000. Phonological correlates of ethnic identity: Evidence of divergence. American Speech 75(2):115-136.

Gordon, Matthew. 2001. Small-town values and big-city vowels: A study of the Northern Cities Shift in Michigan. Durham: Duke University Press.

Herndobler, Robin. 1993. Sound change and gender in a working-class community. In T. Frazer, ed., "Heartland English": Variation and transition in the American midwest, 137-56. Tuscaloosa: University of Alabama Press.

Knack, Rebecca. 1991 Ethnic boundaries in linguistic variation. In P. Eckert, ed., New ways of analyzing sound change, 251-272. San Diego, CA: Academic Press.

Labov, William. 1994. Principles of linguistic change, Vol. 1, Internal factors. Malden, MA: Blackwell.

Labov, William. 2001. Principles of linguistic change, Vol. 2, Social factors. Malden, MA: Blackwell.

Labov, William, Malcah Yaeger, and Richard Steiner. 1972. A quantitative study of sound change in progress. Philadelphia, PA: U.S. Regional Survey.

Mendoza-Denton, Norma. 1997. Chicana/Mexicana identity and linguistic variation: An ethnographic and sociolinguistic study of gang affiliation in an urban high school. Ph.D. diss., Stanford University.

Roeder, Rebecca. 2006. Ethnicity and sound change: Mexican-American accommodation to the Northern Cities Shift in Lansing, Michigan. Ph.D. diss., Michigan State University.

U.S. Census Bureau. 2003. The Arab population: 2000. (Census 2000 brief.) http://www.census.gov/prod/2003pubs/c2kbr-23.pdf (accessed May 15, 2009).

Sai Samant

University of Michigan Department of Linguistics

440 Lorch Hall

611 Tappan Street

Ann Arbor, MI 48109-1220

ssamant@umich.edu 